Pecvnia, 5 (2007), pp. 145-180

\title{
De aprendiz a mercader: El factor en el comercio internacional inglés del siglo XVI
}

J. Lanero Fernández

juan.lanero@unileon.es

E. Ortega Montes

Universidad de León

Fac. de Ciencias Económicas y Empresariales

Campus de Vegazana, $s / n$

24071 León (España)

La aparición de la figura del factor está relacionada con el surgimiento del mercader sedentario. El empleo de factores pasó a ser necesario cuando un mercader aumentaba la escala de sus operaciones y cuando comerciaba con varios países al mismo tiempo. Los factores que vivían y trabajaban en el extranjero eran empleados de sociedades por acciones, mercaderes o consorcio de mercaderes. El factor en sentido genuino podía alternar sus funciones de agente comisionado con el comercio por cuenta propia. El uso de aprendices como factores, al final de una etapa de
The appearance of factors was related to the new figure of sedentary merchants. Factors became necessary when a merchant increased the bulk of his operations and when they traded with various countries at a time. Factors living and working abroad were employed by societies, individual merchants or groups of merchants. A genuine agent could alternate his duties as a commissioned agent with his own trading activities. It was usual that apprentices played the role of factors towards the end of their period of

Ponencia presentada en el $V$ Encuentro de trabajo de historia de la contabilidad: Cervantes y la Real Hacienda, Universidad de Castilla-La Mancha, Toledo, abril 2005. 
aprendizaje, parece que fue una práctica corriente. Los enviaban al extranjero para que adquiriesen experiencia y completasen su educación comercial. El aprendiz no podía comerciar por cuenta propia sin el permiso del patrón que, en cierto modo, era responsable de las acciones de sus aprendices. El conocimiento que tenía el factor del mercado extranjero influía en el patrón a la hora de decidir qué mercancía exportar. Los factores, además de redactar cartas, debían llevar la contabilidad, lo que implicaba conocimientos de teneduría de libros, cambio de divisas y letras de cambio. Las condiciones del comercio exterior fueron acrecentando la responsabilidad del factor $\mathrm{y}$ creando nuevos problemas de representación que no tienen equivalencia en otras relaciones comerciales de la época.

Palabras clave: mercader, factor, comercio exterior, compañía. apprenticeship. They were sent overseas in order to gain experience and complete their commercial education. An apprentice could not trade for his own without his merchant's permission who, to certain extent, was responsible for the apprentices' actions. The knowledge an agent had about a foreign market used to have an influence on the merchant's decision about which goods should be exported. Factors, apart from writing letters, should keep books of accounts, which implied a knowledge of bookkeeping, foreign currencies and bills of exchange. Foreign trade conditions increased factors' responsibilities and created new representation problems which have no equivalence in other commercial relations of the period.

Key words: merchant, agent, foreign trade, company.

La organización del comercio exterior inglés de la segunda mitad del siglo XVI no se ha estudiado con la profundidad que, por su interés y relevancia, merece. Esa falta de interés por los detalles más delicados de la organización comercial que observamos en los trabajos sobre comercio exterior inglés, quizá pueda deberse a dos circunstancias relacionadas entre sí.

En primer lugar, los historiadores se han sentido más atraídos por las sociedades comerciales que por los mercaderes a título individual. Cuando estas Sociedades, o Compañías, eran de capital social y, por tanto, comerciaban como empresas, su estudio implicaba, necesariamente, un análisis sobre la organización y dirección de este tipo de comercio. No estaba permitido que un mercader, a modo personal, realizara actividades comerciales dentro del área de monopolio de la Compañía, salvo que tuviera autorización expresa de ésta. En efecto, la relación del mercader con esas sociedades es de accionista, comerciante privado autorizado o, en algunos casos, empleado de la Compañía. Igualmente, el mercader, en su condición de miembro del Tribunal de Ayudantes, o de la Asamblea General, tenía su función en el diseño de la política comercial de la Compañía, si bien el comercio efectivo que se derivaba de esa política lo 
dirigían los notables de la misma. El mercader que era miembro de una Compañía fusionaba, en cierto modo, su personalidad comercial con la personalidad jurídica que la Compañía tenía en virtud de su licencia. Así pues, las diferentes ramas del comercio que eran monopolios, o que dominaban ciertas Compañías, se pueden estudiar mediante el análisis de las mismas. Siempre que las fuentes sean las adecuadas, lo que no suele ser frecuente, el estudio de esas Compañías podría mostrarnos cómo se organizaba y gestionaba el comercio.

Este enfoque de la organización y práctica comerciales a través de la Compañía, deja de ser satisfactorio en el caso de que el comercio estuviera bajo el control y monopolio de una Compañía regulada por la Corona, pues emitía normas por las que se debían regir sus miembros para llevar los negocios, aunque, dentro de esa normativa, podían comerciar libremente.

Es cierto que las ordenanzas de las Compañías reguladas aclaran, en cierta medida, las prácticas comerciales de sus miembros. Las ordenanzas de los Merchant Adventurers, por ejemplo, documentan la existencia de consorcios formados por sus miembros y el uso de factores o agentes ${ }^{1}$. No obstante, esas ordenanzas no dicen demasiado sobre la relación entre los socios, o entre mercaderes y factores. No podía ser de otra manera; la Compañía regulada no se ocupaba de esos asuntos, salvo que incurrieran en algún tipo de violación de las ordenanzas. Así pues, cuando un tipo de operación comercial estaba bajo control de una Compañía regulada, la historia de ésta, en cuanto Sociedad, nos dice muy poco de la actividad comercial de sus miembros o de la forma en que la llevaban. En el caso de que las Compañías no controlasen alguna clase de comercio, su organización sólo puede inferirse mediante el estudio de los mercaderes y factores implicados en ese comercio.

En segundo lugar, el enfoque directo de la organización comercial, a través del estudio de los mercaderes y de sus relaciones con los factores, ha estado entorpecido por la preocupación por las Compañías y por las dificultades inherentes a ese enfoque. Son dificultades que surgen no tanto por la complejidad de los problemas que se van suscitando, cuanto

\footnotetext{
Véase W.E. Lingelbach, "The Internal Organization of the Merchant Adventurers", Transactions of the Royal Historical Society, 15 (1902), pp. 1-45. Douglas R. Bisson, The Merchant Adventurers of England: The Company and the Crown, 1474-1564, Newark: University of Delaware Press, 1993.
} 
por la falta de los conocimientos necesarios para una comprensión plena de esos problemas. En realidad, es un problema de fuentes. Las Sociedades mercantiles habitualmente dejan pruebas documentales de su existencia. Y el interés que despiertan viene motivado por esas pruebas. Los mercaderes, a su vez, también dejan constancia de sus actividades, aunque suelen ser registros fragmentados $y$, en cierta medida, marginales. Con frecuencia no son los registros de la propia contaduría, toda vez que, del siglo XVI, no se conservan demasiados libros contables de mercaderes o correspondencia con sus factores.

Por consiguiente, las actividades de un mercader hay que reconstruirlas mediante los libros portuarios, testamentos y casos presentados ante los tribunales de justicia, de modo especial, ante el Alto Tribunal del Almirantazgo (High Court of Admiralty). Todas estas fuentes tienen sus dificultades y no menos peligros. Los libros portuarios están incompletos y, en ocasiones, llenos de inexactitudes. Los testamentos pueden contener una estimación demasiado optimista de los recursos del mercader, más que una relación imparcial de en qué consisten esos recursos. Los casos judiciales pueden revelar la patología, pero nos dicen muy poco de la fisiología del cuerpo mercantil. Tampoco conviene exagerar demasiado las cosas, pues los casos judiciales, a la hora de diagnosticar la enfermedad, forzosamente tenían que referirse al funcionamiento de un cuerpo sano. Así, los archivos de casos judiciales aclaran, aunque sea de modo irregular, la relación entre mercader y factor, base importante de la organización comercial del siglo XVI inglés.

II

La aparición de la figura del factor, hasta llegar a ocupar una posición de importancia en la organización del comercio exterior, tiene que ver con el surgimiento del mercader sedentario. Algunos historiadores parecen distinguir tres etapas en la evolución de la práctica comercial.

En la primera etapa, la del mercader viajero, éste lleva sus mercancías a un mercado extranjero, las vende, y luego regresa con los productos que haya podido comprar. En la segunda, la del mercader sedentario, éste permanece en su casa y confía su mercancía a un vendedor (patrón del barco, sobrecargo o factor), que la vende, regresando con otros productos. Por último, está el mercader que sigue siendo sedentario, 
pero que envía su mercancía a un factor, que reside en el extranjero, que la vende y garantiza el envío de cargamento ${ }^{2}$.

Es posible que esta clasificación parezca demasiado simple y esquemática. $Y$, en cierto modo, lo es, pues nos encontramos ante unas divisiones demasiado definidas en el tiempo. Sin embargo, teniendo presente que se valora la complejidad de la organización, y que sus diferentes etapas parecen solaparse, esta retrospectiva parece darnos una buena indicación de cómo los mercaderes reaccionaron ante las condiciones cambiantes del comercio exterior durante un largo período. De igual modo, los gobiernos reaccionaron ante las necesidades cambiantes con la creación de la figura del embajador en residencia.

En la segunda mitad del siglo XVI, el mercader navegante había perdido importancia a favor del sedentario. Ello no implica que los mercaderes ingleses no se desplazaran a Amberes cuando esa ciudad era el centro comercial y de venta de la Europa Occidental y de la Compañía de los Merchant Adventurers. Sería erróneo, no obstante, deducir que sus miembros comerciaban personalmente. Parece que, por lo general, lo hacían a través de factores. Existen indicios de que era una práctica extendida, según se recoge en sus ordenanzas. Los factores representaban a sus patrones incluso ante los tribunales ${ }^{3} \mathrm{y}$, del mismo modo, los Merchants of the Staple podían estar representados por sus factores, o por un abogado, ante los tribunales que su Compañía pudiera tener en el extranjero ${ }^{4}$. Ese no parece que fue el caso del tribunal subsidiario que mantenía la Eastland Company en Elbing, con independencia de que sus mercaderes emplearan factores para dirigir sus negocios ${ }^{5}$. En efecto, el empleo de factores pasó a ser necesario cuando un mercader aumentaba la escala de sus operaciones y, en concreto, cuando comerciaba con varios países al mismo tiempo. Le era físicamente imposible comerciar en persona en sus mercados continentales, todo esto con independencia de

2 Norman Scott Brien Grass, The Early English Customs System: A Documentary Study of the Institutional and Economic History of the Customs from the Thirteenth to the Sixteenth Century, Cambridge, Mass: Harvard University Press, 1918. Philadelphia, 1902, p. 20

W.E. Lingelbach, ed., The Merchant Adventurers, Their Laws and Ordinances,

4 E.E. Rich, The Ordinance Book of the Merchants of the Staple. With an Introduction, Cambridge University Press, 1937, pp. 106, 188.

5 M. Sellers, ed., The Acts and Ordinances of the Eastland Company, London: Royal Historical Society, 1906, pp. 29, 39, 41. 
sus deberes cívicos, que le obligaban a permanecer en Londres o en su lugar de residencia.

El mercader que dirigía sus negocios desde casa podía emplear a un factor viajante para administrar sus intereses en el extranjero, aunque éste parece que solo fue el caso de los países en los que era muy difícil, o imposible, contar con un factor residente. Así, la Russia Company, que comerciaba en calidad de sociedad por acciones, disponía de factores residentes en Rusia, aunque empleaba factores viajantes para el comercio persa. Estos factores llevaban la mercancía a Persia a través de Rusia, la vendían, compraban productos y regresaban. Estas expediciones comerciales persas podían durar cuatro o cinco años, si bien los factores encargados siempre regresaban. La Compañía no llegó a establecer puestos comerciales permanentes en Persia, ni constituyó ninguna organización comercial constante $^{6}$. De modo similar, mercaderes a nivel individual, o un grupo de mercaderes, empleaban factores viajantes para dirigir sus negocios en el Nuevo Mundo, en donde hubiera sido difícil establecer una organización permanente. El envío de factores viajantes a esas regiones no estaba exento de dificultades.

III

Los factores que vivían y trabajaban en el extranjero eran empleados de sociedades por acciones, mercaderes o consorcio de mercaderes. Así, la Russia Company tenía factores en aquel país para que llevaran sus negocios. En ocasiones, aunque no siempre, esos factores eran miembros de la Compañía. Trabajaban en Rusia bajo la supervisión del factor principal, que recibía instrucciones de la Muscovy House de Londres. El factor principal y sus subordinados eran los responsables de vender la mercancía de la Compañía y de asegurar el cargamento de regreso. Les estaba prohibido dedicarse a sus propios negocios, aunque en ocasiones lo hicieron ${ }^{7}$. Igualmente, la East India Company se sirvió de factores para dirigir sus negocios en las Indias orientales. Estos factores estaban clasificados en cuatro categorías, según sus deberes y

6 T.S. Willan, The Early History of the Russia Company, 1153-1603, Manchester University Press, 1956, pp. 59-61; 90-91; 145-155.

7 Ibid., pp. 29-39. 
responsabilidades. Algunos eran designados para ir y regresar en los barcos, aunque otros residían en Oriente. En 1603, la Compañía disponía de factores residentes en Bantam ${ }^{8}$. La Compañía de Levante (Levant Company) también tuvo factores residentes en la zona que le da el nombre, mientras comerció como sociedad por acciones. Todos estos factores percibían un sueldo de la compañía a la que servían?. Por lo general, no estaban autorizados a comerciar con sus propias mercancías, ni para miembros de la Compañía a modo particular, ni para mercaderes ajenos a ésta. Eran servidores de la Compañía con dedicación exclusiva y, como tales, se diferenciaban de los factores de mercaderes, que comerciaban en ámbitos que no estaban vinculados al control monopolista de una sociedad por acciones.

El factor residente, que era empleado de un mercader o de un consorcio de mercaderes, con frecuencia desempeñaba varias funciones. A veces nos puede parecer que alguien actúa de factor de un mercader londinense cuando, en realidad, es uno de sus socios. Así, por ejemplo, en torno a 1585, se considera que Simon Garroway era factor en Marsella, representando los intereses de Henry Farrington y Compañía. A su muerte, miembros de la administración francesa se quedaron con sus bienes y Henry Farrington se vio obligado a desplazarse hasta allí para recobrarlos. Esto puede parecernos un simple ejemplo de las dificultades que generaba la muerte de un factor en el exterior, aunque Garroway no lo era en el sentido estricto del término ${ }^{10}$; era un socio de la Compañía de Henry Farrington, y se le destinó a Marsella para que defendiera los intereses que la Compañía tenía allíi ${ }^{11}$. Esta distribución del trabajo, con un socio en Londres y otro en el extranjero, fue un sistema que se repitió en muchas ocasiones. Un método similar se empleó en el comercio

8 [Henry Stevens of Vermont], The Dawn of British Trade to the East Indies as Recorded in Court Minutes of the East India Company, 1599-1603. Containing an Account of the Formation of the Company, The First Adventure and Waymouth's Voyage in Search of the North-West Passage, Now First Printed from the Original Manuscript by Henry Stevens of Vermont. With an Introduction by Sir George Birdwood, London: Henry Stevens \& Son, 1886, pp. 81-131. Sir William Foster, ed., The Voyages of Sir James Lancaster to Brazil and the East Indies, 1591-1603, London: Printed for the Hakluyt Society, 1940.

9 Sir William Foster, ed., The Travels of John Sanderson in the Levant, 15841602. With His Autobiography and Selections from His Correspondence, London: Printed for the Hakluyt Society, 1931, pp. 130-139.

los demás.

10 En términos legales, en una sociedad todo socio es titular y agente de todos

11 High Court of Admiralty, Examinations, 25, 5 de mayo de 1585. 
nacional, cuando la Compañía de Pañeros de Shrewsbury (The Shrewsbury Drapers) tenía un socio allí y otro en Londres ${ }^{12}$. El que era factor, en un sentido genuino, podía alternar sus funciones de agente comisionado con el comercio por cuenta propia. En 1551 Thomas Cranfield era factor de Vincent Randall en Amberes y, al mismo tiempo, se ocupaba de comprar estambre para venderla en Inglaterra. Ocho años después, Thomas Cranfield era mercader por cuenta propia en Inglaterra y disponía de un factor, E. Smith, en Amberes, que, a su vez, comerciaba con sus propios paños ${ }^{13}$. Es posible que Smith actuara, además de para Cranfield, de factor para otros. Un factor, con independencia de que comerciara o no para sí, podía representar a uno o varios mercaderes.

En 1590, el hijo de Thomas Cranfield, Lionel, era aprendiz de Richard Sheppard; tenía entonces quince años. Seis más tarde lo destinaron a Stade, en donde fue factor de su patrón y de su tío, William Cranfield. En 1597, siendo todavía factor de su patrón, comerciaba, por cuenta propia, con paños y comestibles ${ }^{14}$. El uso de aprendices como factores, al final de su etapa de aprendizaje, parece que fue una práctica corriente. Los enviaban al extranjero para que adquiriesen experiencia y completasen su educación comercial, en la que el aprendizaje de lenguas era importante. No existen pruebas de que estos muchachos fueran al extranjero para trabajar a las órdenes de un mercader local ${ }^{15}$.

El ocho de abril de 1559, Harry Stepney escribía a su patrón, Thomas Sexton, desde Amsterdam:

I am here wythe John Rode at Bord and you shall understand that I go to the skolle to lerne to wrytte duche and to rede yt and to syffer as you have commanded me and for your proffett in tyme to come ${ }^{16}$.

Es indudable que el aprendizaje era la instrucción habitual para un factor, aunque Thomas Fuller recoge el caso de William Johnes,

12 T.C. Mendenhall, The Shrewsbury Drapers and the Welsh Wood Trade in the XVI and XVII Centuries, Oxford University Press, 1953, p. 91.

13 Historical Manuscripts Commission, Calendar of the Manuscripts of MajorGeneral Lord Sackville, Preserved at Knole, Sevenoaks, Kent, Cranfield Papers, 1551-1612, Edited by A. P. Newton, London: His Majesty's Stationery Office, 1940, vol. I, pp. 1-6.

14 Ibid, vol. I, pp. 18-24.

15 T.C. Mendenhall, opus cit., p. 74.

16 State Papers, Supplementary, vol. IX, fols. 124-5. 
que fue desde Monmouth, su tierra natal, a Londres. Posteriormente, mercó con paños de Gales en Hamburgo:

... flying to London, he became first a Porter, and then (his brains being better than his back) a Factour; and, going over to Hamborough, by this industry and ingenuity made such a vent for Welsh Cottons...

Parece que fue un caso excepcional. El curso normal era el que emprendió el factor Richard Clough, que fue aprendiz de Sir Thomas Gresham. El aprendiz, que podía completar su instrucción actuando de factor de su patrón, no podía comerciar por cuenta propia sin el permiso de aquél. El patrón, en cierto modo, era responsable de las acciones de sus aprendices, según nos enseña el caso de Francis Smith.

En 1553, Francis Smith inició su etapa de aprendizaje con William Heyward para un período de nueve años. A la muerte de Heyward, su viuda, Anne, se casó con Thomas Smith, con el que Francis completó su etapa de instrucción. Estando en el último año, Francis fue a Cádiz "aboute the same his master's onlye busynes and affaires, for the onlye use of his master, and as factor to his master and not otherwise". Siguiendo las instrucciones de su patrón, Francis compró diez toneladas de pasas para enviarlas a Inglaterra. Dado que sabía muy poco del producto, encargó a Richard Alcock que se ocupara de comprarlo. Francis no tenía dinero, al parecer, dado que a su patrón no le fue posible enviar paño a España. Edmund Slutter, Thomas Morgan y Anthony Pilborough le prestaron el dinero. Parte de las pasas se enviaron a nombre de Pilborough, y con su marca de mercader. Las condiciones consistían en que, si Thomas Smith aceptaba las letras de cambio en los catorce días vista de la llegada del cargamento, tendría las pasas; de lo contrario, seguirían siendo propiedad de Pilborough. Tomas Smith murió antes de que la mercancía llegara a Inglaterra.

La muerte de su patrón dejó a Francis en absoluto desamparo. Tuvo que pedir prestados cien ducados a un factor, Benjamin Pynnock, y no hubiera podido abandonar España "[without] the helpe of his father dwellinge in Kent to satisfie his expenses and charges there spent, for that he had nothinge to take unto of himselfe". Sacar a su hijo supuso, al

17 [Thomas Fuller], The History of the Worthies of England: Endeavoured by Thomas Fuller, First Printed in 1662. A New Edition, with a Few Explanatory Notes by John Nichols, 2 vols., London, Edinb. \& Perth: Printed for F. C. and J. Rivington et al., 1811, vol. II, p. 120. 
padre de Francis, treinta libras. Además, éste perdió unas diecisiete libras que su padre había entregado a Thomas Smith para que se las diera a Francis "at the fine of his yeres". A la llegada del cargamento, Pilborough ordenó que las pasas no se entregaran. Slutter y Morgan denunciaron a Francis por el dinero que le habían prestado para su patrón. Desconocemos cómo terminó el caso, pero está claro que el punto de fricción estaba en dilucidar si Francis era todavía aprendiz cuando pidió prestado el dinero. Si lo era, no podía pedir dinero para sí, salvo si tenía permiso de su patrón para comerciar por su cuenta. Carecemos de pruebas que demuestren que tenía ese permiso, y existen muchas que lo presentan como "servant and apprentice", que actuaba bajo las órdenes directas de su patrón. Según la viuda de éste, Francis era "as trewe and faithfull a servant as eny man may retayne and kepe". Puede que fuera verdad, pero lo que el caso nos enseña es que, incluso el aprendiz abnegado que actuaba de factor de su patrón, corría ciertos peligros, aunque no tuviera ni un penique de beneficio -según sostiene Francis-, del dinero y mercancía que pasaban por sus $\operatorname{manos}^{18}$.

\section{IV}

Puede que el aprendiz que oficiaba de factor de su patrón se estuviera preparando para el día en que se convirtiese en mercader y patrón de factores. Ése fue el caso de Lionel Cranfield, que ya hemos mencionado, o puede que sólo fuera factor. La combinación de mercader y factor se daba en muchas ramas del comercio. El ejemplo de los Cranfield se desarrolló en Amberes.

En una fecha imprecisa, entre 1568 y 1569, tres factores, Francis Arbieto, Robert Jaques y Simon Watkins, atracaron el barco William en Bayona, en nombre de sus patronos, Richard Foulkes, Richard May, Robert Dove y Thomas Hugget. El William fue asaltado, cerca de Belle Ile, por un barco francés que, al parecer, pertenecía al capitán de esa isla, un destacado ladrón. Saquearon parte de su cargamento: aceite,

18 High Court of Admiralty, Examinations, 15, 25 de junio de 1565; 24, 28 de octubre de 1565; 3 de noviembre de 1565. Los testigos diferían en la fecha en la que Francis comenzó su aprendizaje, que pudo ser en 1554 ó cuando partió para España. 
hierro, resina y ciento doce pistoletas de oro. Según el carpintero del barco, Arthur Carre, los franceses

... with greate torture and payne wounde a rope abowte this juratts and the residew of his companyes hedds and wrested the same to make them confess where more mony remaynid [so that he thought] they wold have wronged his eyes owte of his hed

No parece que los factores sufrieran pérdidas, aunque el patrón del barco llegó a decir que llevaban mercancía propia, además de la de los mercaderes mencionados ${ }^{19}$. De forma similar, a finales de siglo, John Sanderson comerciaba para sí mismo y como factor de la Levant Company:

Nowe I safely arived in Ingland the second time from Constantinople, whear nere seven years I had at that time passed of this wourlds pilgrimage; usinge my smaule stocke, had some imployment for Master Cordell and others, with also factorage profitt of fishes teeth. Five per cent, for all the business I did, except Master Cordells, for which I toke what Wm. Aldrich would alowe $\mathrm{me}^{20}$.

Está claro que se pueden encontrar ejemplos de esta combinación de mercader y factor, aunque no debió ser muy corriente. Las pruebas no son lo suficientemente sólidas como para generalizar, aunque podemos afirmar que el factor que también comerciaba para sí era menos frecuente que el que operaba de forma exclusiva para otros. Puede que existiera cierta renuencia para emplear a un factor que también se ocupara de sus propios negocios, pues es probable que favoreciera sus intereses en detrimento de los de su patrono o poderdante. Además, la bancarrota de un factor, que también tuviera su negocio, podía arrastrar la mercancía de su patrón si no estaba bien diferenciada de la suya ${ }^{21}$.

Gerard Malynes señala en Consvetvdo, Vel Lex Mercatoria (1622), que un factor podía vender su propia mercancía a alguien, pagadera en cierto tiempo, y recibir el dinero en el plazo de pago (Figura 1).

\footnotetext{
19 High Court of Admiralty, Examinations, 17, 26 de septiembre de 1569.

20 Sir William Foster, ed., The Travels of John Sanderson in the Levant, 15841602, ed. cit., p. 17.

21 No está claro si la legislación moderna al respecto sería de aplicación en el siglo XVI. Cfr. Harold Greville Hanbury, The Principles of Agency, London: Stevens \& Sons Limited, 1960, p. 6.
} 
Figura 1: Gerard Malynes, Consvetvdo, Vel Lex Mercatoria (1622)

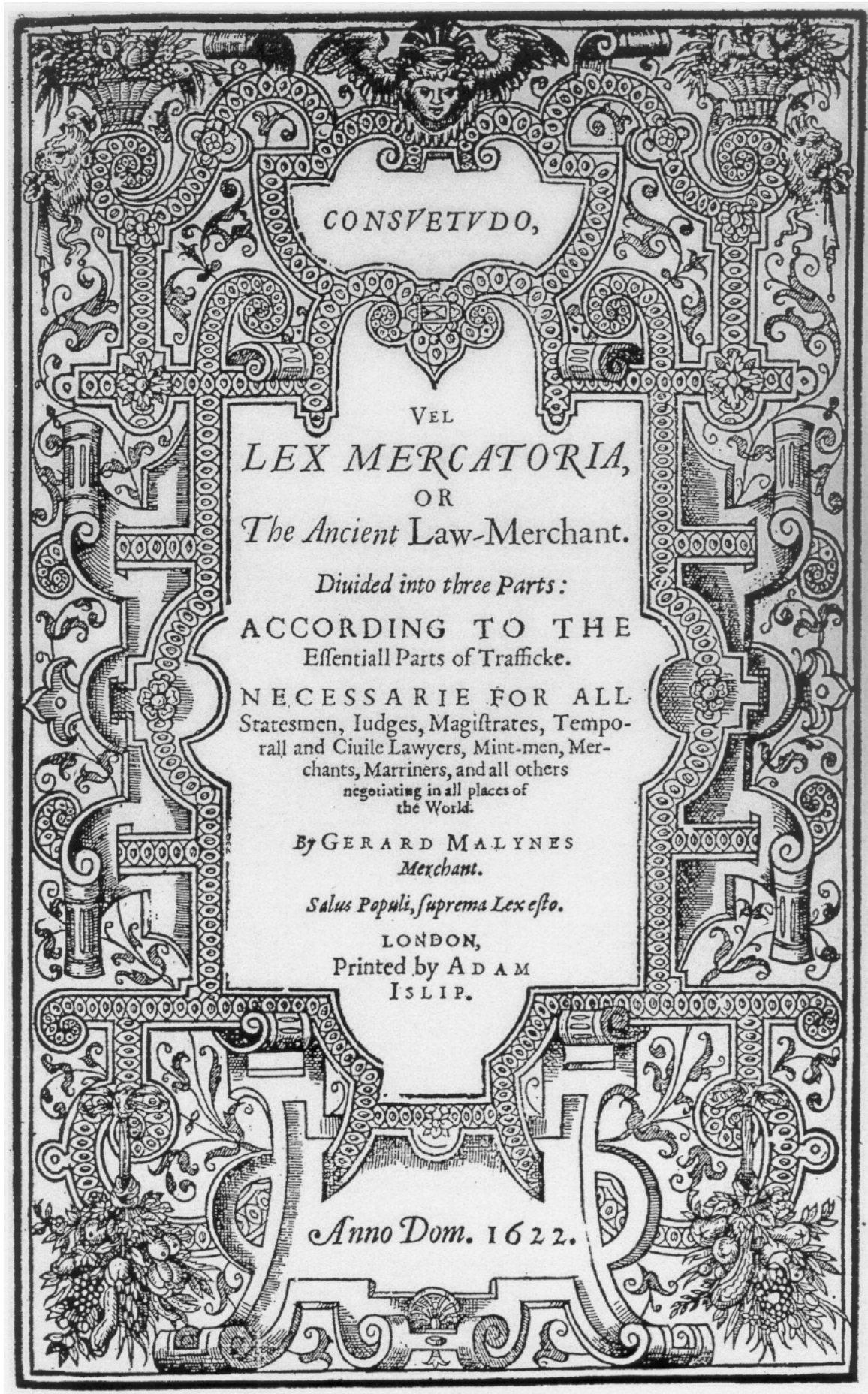


Mientras tanto, en concepto de otra mercancía, vendida con anterioridad, en nombre del patrón, esa misma persona lo tendría pendiente de pago. En ese caso, según Malynes, el factor debe responder por ese dinero que se le adeuda a su patrón, aún cuando no sea capaz de recuperarlo:

If a Factor doe sell goods to another man payable at time for his owne account and reciueth the money for the same at the time of payament, and in the meane time letteth other mens monyes remaine in that mans hand vnpayed for goods by him formerly sold; this Factor is to be answerable for taht money vnto those other men, although hee should neuer recouer one penny of it. For hee cannot (without fraud) beare with the nonpayment of other mens monies after they be due, and procure the payment of his owne money, to another mans losse and preiudice ${ }^{22}$.

Este conflicto de intereses entre el factor como comerciante y el factor en su condición de tal, puede surgir con facilidad cuando ambos papeles recaen en la misma persona.

Este factor, comercie o no para sí mismo, podía representar a un mercader o a varios. Así, Blase y John Freman, que actuaron de factores de Thomas Sexton en Danzig, también representaron a otros comerciantes, aunque tuvieron la oportunidad de hacerlo para los familiares de Sexton. Estos dos factores eran hermanos. Blase, que era el mayor, ostentaba una especie de prevalencia, lo que explica que, al escribir a su patrón, diga: "I have lay dyne for you". Mientras que su hermano señala: "me brother have layden for you"23. En este respecto, difieren de los dos factores de Sir Roger Martin en Hamburgo, hacia 1570, que tenían la misma posición ${ }^{24}$. Un mercader debía tener gran experiencia de comerciante, y a gran escala, para emplear a dos factores en la misma plaza. Sexton lo hizo en Danzig. Su factor en Cádiz, George Lawson, también lo era de, al menos, otro mercader. De modo parecido, el factor de Sexton en Lisboa,

22 [Gerard Malynes], Consvetvdo, Vel Lex Mercatoria, or The Ancient LawMerchant. Diuided into three parts: According to the Essentiall Parts of Trafficke. Necessarie for All Statesmen, ludges, Magistrates, Temporall and Ciuile Lawyers, Mint-men, Merchants, Marriners, and All Others Negotiating in All Places of the World. By Gerard Malynes, Merchant. Salus Populi, Suprema Lex esto. London: Printed by Adam Islip, 1622, pp. 112-113.

23 State Papers, Supplementary, vol. IX, fols. 13-14, 41, 51.

43.

24 T.S. Willan, The Early History of the Russia Company, 1553-1603, ed. cit., p. 
trabajaba para más de un mercader ${ }^{25}$. La práctica de comerciar en varios lugares al mismo tiempo debió significar que únicamente los mercaderes más importantes operaban a un nivel que les permitiera monopolizar los servicios de un factor en cada uno de estos centros comerciales.

Según Malynes, "Factors doe deale most commonly for diuersmen..."26. En efecto, así sucedía. En 1588, Thomas Alabaster era factor en España de Robert Brooke, Hugh Lea y otros mercaderes. Por culpa de la Armada Invencible, no era un momento demasiado propicio para el comercio inglés en España. El astuto Alabaster se sirvió de un francés para comprar y vender la mercancía ${ }^{27}$. En 1593, Richard Billett era factor en Caen de Randolph Symes, Robert Bromley y Thomas Tidder, para los que compraba telas. También era factor de otros mercaderes ingleses, como Mr. Hawes de Londres, a quien se lo había recomendado el propio Bromley ${ }^{28}$. En ocasiones, un factor parecía actuar para cierto número de mercaderes, si bien, en la práctica, lo hacía para un consorcio.

En 1585, William Resould era factor en España y Portugal de Oliver y Nicholas Stile, Simon Lawrence y Henry Colthurst. En realidad, estos mercaderes constituían la sociedad de Henry Colthurst y Compañía ${ }^{29}$.

\section{V}

El factor, con independencia de que estuviera al servicio de uno o varios mercaderes, se ocupaba, fundamentalmente, de vender y comprar. Recibía y vendía la mercancía de su patrón al mejor postor, y compraba y enviaba la mercancía que su patrón le ordenaba. Puede parecernos una acción mecánica. No lo es. El factor no era un agente pasivo; naturalmente, no decidía la política de su patrón, aunque el

25 State Papers, Supplementary, vol. IX, fols. 22, 103-104.

26 Gerard Malynes, opus cit., p.112.

27 High Court of Admiralty, 27, 14 de marzo de 1588.

28 Ibid., 30, 13-14 de marzo de 1593 y 14, 16 y 23 de mayo de 1593.

29 Ibid., 26, 19 de enero de 1587. Calendar of State Papers, Domestic Series of the Reign of Elisabeth, 1591-1594, Preserved in Her Majesty's Public Record Office, Edited by Mary Anne Everett Green, London: Longmans, Green, Reader and Dyer, 1867, p. 66. Court of Requests, Proceedings, $75 / 30$. 
consejo e información que le suministraba, influía. Su relación con el patrón era, a pequeña escala, semejante a la que tenían los ministros con la reina. El conocimiento que tenía el factor del mercado extranjero influía en el patrón a la hora de decidir qué mercancía exportar.

Blase Freman, por ejemplo, aconsejó a su patrón, Thomas Sexton, sobre qué paños eran los mejores para vender en Danzig. Con frecuencia era muy crítico con la mercancía que le enviaba, y se sorprendía de que Sexton mandara "soche begery ware", como algodón comido por los gusanos. Además, le suplicaba "for lofe of God" que no enviara más. Freman no veía la forma de comprar hilo de cable, para el que necesitaba dinero en metálico, cuando no recibía más que paños en mal estado que no podía vender. Así mismo, el factor suministraba información de los precios y cantidades de los productos extranjeros disponibles para su envío a Inglaterra. Semejante información influía en el mercader a la hora de decidir sus importaciones. De vez en cuando, el factor no sólo tenía que suministrar la mercancía, sino también intervenir en su fabricación, y de ese modo, Blase Freman compró hilo de cable en Danzig y lo tuvo que convertir en cables y cabos antes de su envío a Inglaterra ${ }^{30}$. Puede que fuera excepcional que los factores se responsabilizaran de los productos que enviaban pero, cuando menos, tenían que cerciorarse de que estaban listos para el embarque. En Marruecos, los factores tenían que supervisar "the cranage, paperinge, thredinge, custuminge and shipping" del azúcar ${ }^{31}$.

Toda esta actividad implicaba gran cantidad de correspondencia, de la que se conserva muy poca. Al mismo tiempo que la mercancía de un mercader se distribuía en varios barcos, por razones de seguridad, el factor redactaba sendas cartas suministrando esa información y enviándolas en barcos diferentes. Entre el 27 de junio y el 4 de julio de 1557, Blase y John Freman escribieron quince cartas a su patrón, que salieron de Danzig en, al menos, siete barcos. Estas cartas no eran idénticas, pero cada una contenía la misma información. Una carta describía, además de la mercancía de Sexton en el barco que la llevaba, la mercancía de los otros barcos. Así, la mayoría de las cartas daban una información detallada de todos los envíos de Freman ${ }^{32}$.

30 State Papers, Supplementary, vol. IX, fols. 8-14.

31 High Court of Admiralty, Examinations, 16, 3 de enero de 1569.

32 State Papers, Supplementary, vol. IX, fols. 38-53v. 
Sería interesante saber si los factores empleaban a escribientes para su correspondencia. No parece que fuera el caso de los Freman. A veces, los factores empleaban a sirvientes, aunque no están claras las tareas que les encomendaban ${ }^{33}$.

Además de redactar cartas, los factores debían llevar la contabilidad, lo que implicaba tener conocimientos de teneduría de libros, cambio de divisas y letras de cambio. Desafortunadamente, poca información nos ha llegado al respecto.

\section{VI}

Es indudable que el factor adquiría conocimientos de la práctica comercial durante los primeros años de su instrucción. Parte de ese conocimiento le venía dado por la práctica y por la enseñanza oral. Resulta más dudoso que el factor lo adquiriese en la lectura de tratados publicados.

En la década de 1550, el factor podía estudiar contabilidad sirviéndose del libro de James Peele, The maner and fourme, aparecido en 1553. Este tratado dispone de un modelo de libros de cuentas, referentes a un tal Fraunces Bonde, tendero de Londres. Hay que admitir, no obstante, que poco podía extraer de este libro un factor inmerso en el mercado internacional ${ }^{34}$. Años más tarde, y también de la mano de James Peele, el factor pudo buscar instrucción en su segunda obra: The Pathe waye to perfectnes, publicada en 1569. El modelo de libros de cuentas es mucho más elaborado, y corresponde a un tal Frauncis Twyforde, ciudadano y mercero de Londres ${ }^{35}$.

33 High Court of Admiralty, Examinations, 26, 13 de enero de 1587.

34 [James Peele], The maner and fourme how to kepe a perfecte reconyng, after the order of the moste worthie and notable accompte, of Debitour and Creditour, set foorthe in certain tables, with a declaration therunto belongyng, verie easie to be learned, and also profitable, not onely unto suche, that trade in the facte of Merchaundise, but also unto any other estate, that will learne the same, 1553. Imprinted at London, by Richard Grafton, printer to the Kinges Maiestie. Cum privilegio ad imprimendum solum.

35 [James Peele], The Pathe waye to perfectnes, in th'accomptes of Debitour, and Creditour: in manner of a Dialogue, very pleasaunte and proffitable for Merchauntes and all oth' that minde to frequente the same: once agayne set forthe, and verie muche enlarged. By lames Peele Citizen and Salter of London, Clercke of Christes Hospitall, practizer and teacher of the same. Imprinted at London, in Paules Churchyarde. By Thomas Purfoote, dwellinge at the signe of the Lucrece. Wisdome and Science, Preuent Indigence, 1569 (fechado a mano, de forma errónea, en 1566). 
A buen seguro que los factores tuvieron la oportunidad de aprender bastante más al leer el tratado de John Weddington, A breffe instruction, publicado en Amberes en 1567. Debemos tener presentes varios aspectos de este tratado ${ }^{36}$. John Weddington fue factor de Sir Thomas Gresham y, posteriormente, se convirtió en mercader. Su obra se imprimió en Amberes, pues allí era donde ejercía la representación de los intereses del destacado mercader inglés. Y en su libro, como era de esperar, existe un apartado específico en el que se ocupa de la contabilidad que deben llevar los factores.

Sin embargo, no se publicó ningún manual para factores, de carácter general, hasta la aparición, en 1589, de The marchants avizo, escrito por "[that] hartie wellwiller in Christ. I. B. Marchant" ${ }^{37}$. Se trata de un tratado escrito por John Browne, mercader de Bristol, que tenía intereses comerciales en España y Portugal. Las instrucciones que recoge son válidas para cualquier factor, con independencia del país en el que esté destinado.

The marchants avizo (Figura 2) está pensado para los hijos y sirvientes de los comerciantes en su primer viaje al extranjero. Es ciertamente moralizante en el tono, y hace hincapié en la necesidad de la oración diaria y en evitar las tentaciones de este mundo. En consecuencia, el factor debe

First seeke the kingdome of God and the righteousness thereof: and then all things shall be giuen the that thou hast neede of.

Y se le exhorta:

Be not greedy nor in lust after that, which is both displeasant vnto God; hurtfull to thy body; an enemy to thy soule; and a shortner of thy life: which is, Wine, Wealth and Women ${ }^{38}$.

36 [John Weddington], A breffe instruction, and manner, how to kepe, marchantes bokes, of Accomptes, After the order of debitor and creditor, as well for proper accomptes, partable, factory, and other, \& c. Verry nedefull to be knowen, and vsid of all men, in the feattis of marchandize. Nowe of late newly, set forthe, and practisyd. By lohan Weddington cyttizen of London. Prenttyd in Andwarpe by Petter van Kerberghen, 1567.

37 John Browne, The marchants avizo. Cfr. Juan J. Lanero Fernández, De cómo los ingleses deben gestionar sus negocios en la península ibérica: The marchants avizo (1589), Universidad de León, 1995. En el estudio introductorio se da cuenta de la biografía del autor del manual y se estudian las numerosas ediciones que conoció la obra.

38 Juan J. Lanero Fernández, opus cit., Anexo I, pp. 55-56. 
Figura 2: John Browne, The marchants avizo (1589)

\section{THE \\ MARCHANTS AVIZO \\ VERY NECESSARIE FOR THEIR sonnes and seruants, when they first send them be- yond the seas, as to Spaine and Portingale or other countreyes. \\ Made by their hartic wellwiller in Christ. I.B. Marchant. ECCLEs. 40.18.}

To labour and to be content with that a man hath, is a sweet life: but the feare of God is aboue all, \&c.

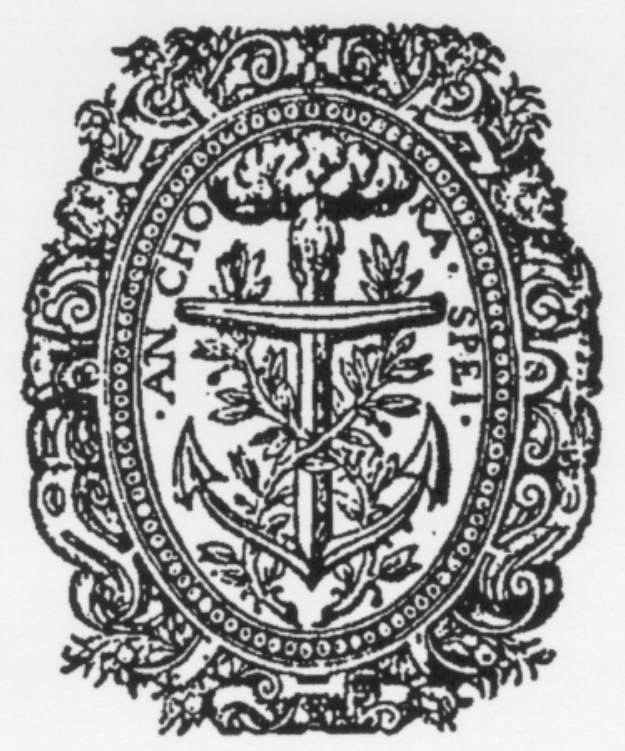
Imprinted at London by Richard Field for Wil- liam Norton,dwelling in Paules Churchyard at the signe of the Queenes armes. 1589.

Reconstrucción de la primera edición desaparecida. 
El ansia de dinero puede incluirse en los pecados de la carne, aunque, en realidad, The marchants avizo advierte que la devoción es una ayuda valiosa para alcanzar la prosperidad material.

A un nivel más práctico, la obra aconseja al joven factor sobre cómo tratar a los mercaderes extranjeros y a los ingleses de la competencia. Además, proporciona ejemplos de instrumentos del comercio: conocimiento de embarque, letra de cambio, poder notarial, pagarés, póliza de seguros y la estructura de una cuenta española:

Here followeth the forme of a Spanish accompt and howe to make a bill of lading, a letter of remembrance, a bill of exchange, a bill of debt, an acquittance, a letter of Atturney, an obligacion, and a Policie for assurance. \& c. ${ }^{39}$

Quizá la sección más importante sea la que está dedicada a modelos de cartas que el factor debe utilizar para escribir a su patrón y también "[to] instruct yong nouices, to vse greater breuitie in their writings then commonly they are wont" 40 .

La primera carta se ocupa, y además de modo apropiado, de que el barco en el que viaja el factor sea conducido a un puerto erróneo. Al llegar a su destino, el factor deberá informar a su patrón de su llegada mediante una carta:

Touching Sales or Implements [purchases], I doe vnderstand that it wil not fall out so well as I wished or hoped it would: but I will do my verie best indeuour for you according as time serue ${ }^{41}$.

El patrón, una vez que ha sido advertido de ponerse en lo peor, está preparado para recibir carta de su factor en la que le describa qué mercancías se han comprado y vendido y a qué precio. Una carta subsiguiente le dará detalles de los productos que el factor ha enviado. Se insiste en que la brevedad de estas cartas es suficiente hasta que el factor, por la práctica, aprenda a escribir las suyas propias. Puede que la brevedad no permita escribir todo lo que el factor desea decir a su

39 Ibid., Anexo I, pp. 26-53.

40 Ibid., Anexo I, Dedicatoria, y pp. 12-18.

41 Ibid., Anexo I, p. 13. 
patrón, pero estas cartas son fiel reflejo de la clase de correspondencia que utilizaban los factores isabelinos.

El factor debe ejercer diligencia, consciencia, silencio y paciencia, según le ordena The marchants avizo; aún así, su posición no era nada fácil. Algunas de las dificultades podían surgir de la relación legal entre el factor y su patrón. Este aspecto -interesante a la vez que oscuro- no se ha analizado, aunque tiene importancia para comprender los entresijos de la organización comercial.

Según Gerard Malynes, existe una diferencia clara entre un factor y un sirviente:

The difference betweene a Factor and a Seruant consisteth chiefly in this, That a Factor is created by Merchants Letters, and taketh Salarie or prouision of Factoridge: But a Seruant or an Apprentise, is by his Master entertained, some receiuing wages yearely, and some others without wages ${ }^{42}$.

Además,

A Factor is bound to answere the losse which happeneth by ouerpassing or exceeding his Commission; whereas a Seruant is not, but may incurre his Masters displeasure. For albeit that the Spanish Prouerbe is Quien Passa commission, pierde Prouision, that hee that exceedeth his Commission shall lose his Factoridge ${ }^{43}$.

Es probable que esta distinción entre el factor y el sirviente, en la práctica, sea una diferenciación entre el factor y el aprendiz que actúa como factor. Fuera de factor y aprendiz, el empleo de sirvientes, en el sentido que Malynes concede al término, no parece que fuera frecuente. El problema real es el que concierne a la responsabilidad y obligaciones del factor.

La afirmación de Malynes de que el factor "[was] created by Merchants Letters", conlleva que la designación del factor se fundamenta en un instrumento escrito formal, aunque dudamos de que siempre fuera así. Un proceso judicial ante el Alto Tribunal del Almirantazgo (High

42 Gerard Malynes, Consvetvdo, Vel Lex Mercatoria, ed. cit., p. 111.

43 Ibid. 
Court of Admiralty), de 1594, provocó varias y contrapuestas opiniones al respecto. George Clough sostenía que un factor

... must have his power of factoridge eyther in writinge or by letters of advice, excepte a merchante put suche truste in his factor that he referieth all to his discretion by worde of mouthe, without writing, which is not usuall.

De igual modo pensaba James Askewe, que sostenía que un hombre debe tener autorización, por carta o escrito, antes de convertirse en factor de un mercader, si bien éste puede autorizar a su factor de palabra.

Según John Stokes, muchos factores eran designados sin ninguna autorización escrita, pues les bastaba que se les reconociera como tales.

John Burd va más lejos. Defiende que no sólo es innecesario designar a un factor por escrito, sino que esto, en sí mismo, no lo convierte en factor. La prueba real era más sencilla; si un mercader encomendaba su mercancía a una persona y le daba instrucciones para que la vendiera, esa persona se convertía en factor del mercader. Así, Robert Walde consideraba "a factor to be one that doth business for a marchante and hath allowance for his factoridge" 44 .

Está claro que la prueba de la condición de factor no se basaba en una designación escrita, sino en las acciones del factor. Si una persona actuaba para y en representación de un mercader, se le consideraba su factor. En la práctica era una costumbre que funcionaba. Una persona podía ser factor sin autorización escrita, del mismo modo que alguien podía, y puede, ser inquilino sin contrato formalizado.

Con independencia de que fuera o no designado, el factor necesitaba recibir instrucciones de su patrón. Parece que existía el acuerdo de que el factor que se apartaba de esas instrucciones, lo hacía a sus expensas. Así lo advierte The marchants avizo:

Firstly carie this for an especiall note, that whensoeuer you haue dealings for anie marchants, you do in all things and euerie point obserue according to 
their comision and direction. For although I knowe, it will sometimes seeme to your selfe, that you shall better please your marchant, not to buy those wares which he appointeth, because of the dearenesse of them: yet (I say) you shall giue euer more best contentment to your marchant and saue your selfe harmelesse, when you followe his owne order and remembrance ${ }^{45}$.

Del mismo modo, Malynes cita varios ejemplos de las penas que pueden padecer los factores que desobedecen las instrucciones de sus patronos. Así pues,

If a Factor doe sell a commoditie vnder the price limited vnto him; he is to make good the losse or difference of the price, vnlesse he can giue a sufficient reason of his doing so: wherein hee is to consider the disposition of the Merchant for whom hee dealeth...

Si un patrón ordena comprar una mercancía a su factor, y éste la comprara a precio más alto del estipulado por aquél, puede que se tenga que quedar con ella si su patrón la rechaza. Todo esto, al menos en teoría, puede ser cierto pero, en la práctica, como el propio Malynes admite, es imposible que un patrón dé instrucciones sobre todos los aspectos, por lo que resulta conveniente que el mercader elija un buen factor para conferirle amplios poderes:

This Good Factor therefore may bee trusted, and all Commissions giuen vnto him may be ample, with addition of these words, Dispose, doe \& deale therein as if it were your owne; $\&$ this being so found; the Factor is to be excused, although it should turne to losse, because it is entended hee did it for the best according to his discretion, which is and ought to be the truest director, making a conscience to see their Masters losse, if they can preuent it $^{46}$.

El mercader se arriesgaba si otorgaba al factor plenos poderes, pues podía afectar a la situación legal de la mercancía. En efecto, cuando un factor disponía de esos poderes, la propiedad de la mercancía se transfería al patrón una vez que se estampaba su marca de mercader. Ése no era el caso de cuando el factor sólo disponía de autorización

45 Juan J. Lanero Fernández, opus cit., Anexo I, p. 10.

46 Gerard Malynes, Consvetvdo, Vel Lex Mercatoria, ed. cit., pp. 111-113. 
limitada. La concesión de total discreción a un factor, según parece, era excepcional.

El factor que recibía instrucciones de su patrón y las ejecutaba, quedaba libre de toda responsabilidad, aunque en la práctica podía verse en apuros si el patrón cuestionaba su buena fe. En 1565, John Broke acordó con John Bancks que fuera su factor en España. Broke explicaría más tarde que Bancks

... was no generall factor, but a speciall or particular doer or attornye [for him], to doe suche his affaires in Spaine as he (...) should and doe geve him the saide Bancks from time to tyme in particular commission or lettres missives or other wise.

Pues bien, el 5 de febrero de 1565, Broke escribió a Bancks pidiéndole que pagara una deuda de tres mil livres tournois a Peter Cole. A su decir, Broke "[was] verye sorrye that he ys soe longe unepayde". En caso de que fuese necesario, Bancks podía cargarle quinientos o seiscientos ducados al cambio, con el fin de liquidar la deuda. Bancks pagó lo que Broke debía y regresó a Inglaterra, pues Broke pensaba que "mayebe yowe have bynne long ther abowghte lytell to my proffyte as yt aperes".

Conviene, no obstante, que observemos el desarrollo de los hechos. Siguiendo las instrucciones de Broke y utilizando su carta como autorización, Bancks pidió prestados seiscientos ducados en nombre de su poderdante, que utilizó para saldar su deuda. De los seiscientos ducados, doscientos se los prestó Nicholas Atkins, al que Bancks extendió dos letras de cambio pagaderas por Broke. Sin embargo, éste se negó a aceptarlas con la excusa de que Bancks no había utilizado el dinero según sus órdenes. Atkins inició acciones legales contra Bancks en España y, posteriormente, denunció a Broke por los doscientos ducados.

Broke, que no lo tenía fácil, declaró que era costumbre entre mercaderes

... that if a generall factor doe send lettres of exchaunge to his master, where business he procurethe, for the payment of eny money, that then the said master uppon receipte of the saide lettres is bounde to the payment of the said money. And the like custom hathe place when a particuler factor observing and fulfillinge the particuler commission of his master hathe in that respect taken upp money by exchaunge, and therewith chardgithe by his lettres of exchaunge his master or him whose busines in particuler he procurethe. 
Banck había cumplido la función para la que su patrón lo había comisionado. No parece que se apropiara del dinero en beneficio propio $\mathrm{y}$, aunque lo hubiera hecho, es probable que Broke hubiese tenido que devolvérselo a Atkins, y luego denunciar a Bancks. El veredicto condenó a Broke a pagar a Atkins la cantidad de cuarenta y tres libras 8 s. 9 d. Ignoramos por qué se fijó esa cantidad, pues el ducado, al cambio, equivalía a $6 \mathrm{s.}^{47}$

La normativa de aduanas se invocaba con cierta frecuencia, y podía dar alguna protección a los factores, pero no era de aplicación en todas las operaciones. Así, es difícil averiguar qué se podía inferir, por ejemplo, ante el caso de Richard Butler que, en 1574, era factor en España de Robert Warner, del que recibió cuarenta piezas de paño de Kersey. Butler tenía que venderlas y enviar el importe en metálico o en pagaré a cobrar en destino. En Bayona vendió treinta y cinco a siete ducados y cuarto; las cinco restantes las vendió a un mes vista: cuatro a ocho ducados y cuarto, y una a ocho. Después de pagar trece ducados y siete reales por el flete, la aduana y otros impuestos, Butler intentaba enviar el resto del dinero obtenido por las treinta y cinco piezas de Kersey. Según su propio relato, él y otros mercaderes ingleses se dirigían, en Bayona, hacia el barco Jonas, cuando se vieron perseguidos por soldados españoles. Sabían que era delito sacar dinero español del país y que, en el caso de que algún extranjero "be taken soe doinge, he loosethe not onelye the monye, but allsoe all his goodes in that countrye and (...) his bodye is subjecte to punishment there appoynted for felones" ${ }^{\prime 4}$. Ante esta tesitura, Butler y los demás arrojaron el dinero al mar; los registraron pero nada les fue encontrado. Warner denunció a Butler alegando que era frecuente sacar dinero de España, que la justicia española nunca había sorprendido a nadie con dinero y que, a fin de cuentas, nadie había perseguido a Butler. Éste aceptó responder por las cinco piezas vendidas a crédito, pero la decisión se volvió en su contra. Tuvo que pagar a Warner el total de las cuarenta piezas, estimado en ochenta libras, una vez deducidos los gastos. No se dieron razones para adoptar esta decisión. La escasez de pruebas irrefutables indica que el veredicto se basó en que,

47 Citado en T.S. Willan, Studies in Elizabethan Foreign Trade, Manchester University Press, 1959, p. 23. Véase también High Court Of Admiralty, Examinations, 16, 16 de abril de 1567; 11, 23 de octubre de 1567, 25 de noviembre de 1567, 24 de enero de 1568. Libels, 38, nos. 41,$42 ; 39 ; 39$, nos. 75, 95, 107; 40, no. 127.

48 Citado en T.S. Willan, Studies in Elizabethan Trade, ed. cit., p. 23. 
o Butler fue presa del pánico, o ni se estremeció; en que pudo escapar con el dinero para su patrón o en que huyó con el dinero para sí mismo ${ }^{49}$.

La relación del factor con su patrón conllevaba obligaciones que eran complicadas y objeto de polémica. Ésa era la situación cuando el factor trabajaba para un único patrón; cuando lo hacía para varios mercaderes, sus obligaciones eran más complejas. Lo mínimo era que sus operaciones, en nombre de varios mercaderes, podían verse mezcladas, en lugar de mantenerlas separadas. Así, en 1568, Thomas Cartwright era factor en Amberes de Thomas Longton, que debía a Lucas Stayerd ciento sesenta y seis libras por mercancía recibida. Parte de la misma la aprehendió el propio Stayerd, presumiblemente en prenda de la deuda. Al mismo tiempo, Cartwright recibió cuarenta piezas de paño de Kersey, por comisión, de Stephen Woodroff, que entregó a Stayerd con la confianza de "to advoyde the utter losse of them that ellse myght have happenid by the generall arrest there made by the Duke of Alva". Stayerd interpretó que las piezas pertenecían a Longton y que se las habían dado como pago, o parte del pago, de la deuda de éste. Desconocemos el veredicto del caso judicial de Woodroff contra Longton, si bien el caso mismo demuestra que un factor que representara a dos mercaderes podía mezclar sus negocios respectivos ${ }^{50}$.

El factor que representaba a varios mercaderes también podía verse involucrado en dificultades legales por la propiedad de la mercancía que pasaba por sus manos. En 1592, Richard Billett era factor, en Caen, de Randolph Symes, que envió a uno de sus sirvientes para que inspeccionara las cuentas de Billett y se hiciera cargo de la mercancía y del dinero que obraba en su poder. Billett pidió a Symes un tiempo para cuadrar sus cuentas; entre tanto, se comprometía a enviar tela para velamen, ocho toneladas de aceite y ciento veintiocho coronas francesas. Dado que Billett oficiaba también para otros mercaderes, después de identificar dos fardos de tela con la marca de Symes, los embarcó a nombre de George Oliver. Como es lógico, Symes reclamó la mercancía, pues la consideraba parte del finiquito con Billett. Desconocemos cómo acabó la disputa. No obstante, hay que recordar que si un factor actuaba para un único mercader, se entendía que la mercancía que adquiría era

49 High Court of Admiralty, Examinations, 21, 3 de mayo de 1575, 13 de junio de

50 High Court of Admiralty, Examinations, 17, 1 de julio de 1569. 
para él. Si lo hacía para varios, era imposible decir a quién pertenecía hasta que se marcaba. De este modo, un factor que representaba a varios mercaderes podía comprar mercancía y enviarla a cualquiera de ellos. Ninguno podía reclamar su propiedad hasta que el factor lo indicara con la marca de alguno de ellos. Una vez marcada la mercancía, las marcas no se podían modificar, y los productos no se podían enviar a otro mercader. Resulta obvio, por este caso y por otros muchos, que las marcas de los mercaderes eran muy importantes a la hora de identificar mercancía y adscribir su propiedad ${ }^{51}$.

VII

Estos aspectos legales indican que una maquinaria complicada se había puesto en marcha para regularizar el comercio exterior inglés. Sería exagerado defender que en esta maquinaria, por lo demás rudimentaria, ya existían disposiciones de algún tipo de legislación sistemática de representación comercial. Éste fue un desarrollo posterior. Lo que aquí nos encontramos son los problemas que esa normativa debió solucionar. La relación entre principal y agente no se reducía, tan solo, al comercio exterior; tampoco la de mercader y factor, si bien las condiciones de ese comercio exterior fueron acrecentando la responsabilidad del factor y creando nuevos problemas de representación que no tienen equivalencia en otras relaciones comerciales de la época.

El propio factor creía que verse involucrado en un caso ante un tribunal inglés era menos preocupante que la posibilidad de encontrarse ante un tribunal del país en el que trabajase. El mercader sedentario arriesgaba su capital; el factor ponía en peligro su libertad o su vida. Muchos eran los escollos que se le presentaban y, de modo especial, en territorio español. En 1559, Edward Castelin y Anthony Hickman destinaron a dos factores a las Islas Canarias, Thomas Nicholas y Edward Kingsmill, que fueron arrestados por infringir la normativa comercial y por ofensas a

51 Se conservan marcas de mercaderes en la High Court of Admiralty y en los Libros Portuarios. Cfr. Exchequer, King's Remembrancer, Port Books, 1131/II, 1323/I. Véase también Edward Mars Elmhirst, Merchants' Marks, Ed. Leslie Dow, London: Publications of The Harleian Society, 1959. 
la religión. Kingsmill fue multado con mil ducados, y Nicholas encarcelado cuatro años ${ }^{52}$.

En 1585, William Resould, factor en Bayona, fue encarcelado, y sus paños y dinero incautados porque, supuestamente, no había observado el embargo comercial impuesto por los españoles. Se llegó a afirmar que los patrones de Resould perdieron tres mil quinientos veintitrés ducados ${ }^{53}$.

El embargo mencionado, motivado por la confiscación, por parte de la reina Isabel, del tesoro español, en 1568, significó un tratamiento penoso a un grupo de factores, en 1572. A comienzos de ese año, varios mercaderes londinenses enviaron paños y otras mercancías en el Primrose, con destino a Viana y Caminha, en Portugal. Cinco factores, Paul Baning, Robert Shart, John Fisher, Martin Goswell y John Halsont embarcaron en el Primrose para vender el cargamento. Se registraron como factores y pasajeros. Es posible que alguno fuera a ocupar un puesto de factor residente. Ése fue el caso de Baning, que llevaba órdenes de cargar aceite en otro barco en Sanlúcar de Barrameda. Cuando el Primrose llegó a las Islas de Bayona, los factores tomaron tierra en un bote de pesca y vendieron cuatrocientos paños de Suffolk a unos mercaderes de Viana y Caminha, que enviaron tres barcas para recogerlos; una vez cargados, partieron para Portugal. Los factores, que ya habían regresado al Primrose, tomaron un bote de pesca para acercarse a Portugal y recoger el importe de los paños. Sin embargo, se encontraron con dos pinazas de Vigo, en pie de guerra, que abordaron el bote y llevaron a los factores "away withe much crueltie shewed them unto the towne of Vigo, where they were imprisoned in moaste extremest sorte, and noe man permitted ne suffred to come and speake withe them" 54 .

Por consiguiente, las dificultades en las que podía verse envuelto el factor podían provenir de decisiones arbitrarias y de la

52 Cfr. L. de Alberti and A. B. W, Chapman, "English Traders and the Spanish Inquisition in the Canaries", Transactions of the Royal Historical Society, Third Series, III, 1909, pp. 237-253. Las desventuras de Thomas Nicholas en las prisiones españolas, y su posterior liberación a instancias de la mismísima Isabel I, que intercedió ante Felipe II, están recogidas en Julio-César Santoyo, "Thomas Nicholas y el cronista de Indias Agustín de Zárate. Comentarios lingüísticos e históricos sobre la traducción inglesa de 'La Conquista del Perú' (1581)", Boletín Sancho el Sabio, Año XVIII, Tomo XVIII, 1974, pp. 555-578. Las paradojas de la historia convirtieron a Nicholas en traductor de Zárate.

53 High Court of Admiralty, Examinations, 26, 19 de enero de 1587.

54 High Court of Admiralty, Examinations, 19, 30 y 31 de mayo de 1572, 5 de junio de 1572; Libels, 44, no. 252. 
legislación estricta de los extranjeros con los que trabajaba, aunque también de errores sólo achacables al factor. En 1582, Nicholas Tayler era factor de John Lambert en La Coruña, donde fue encarcelado por no inscribir el dinero que había percibido por la venta de la mercancía de su patrón. Por causa de su encarcelamiento, Tayler gastó el dinero, por lo que nada pudo mandar a su patrón en el barco Fortune. Tayler viajó a Bayona, donde pidió prestados ochenta ducados a William Heaton, pagaderos en Londres por Lambert. Con este dinero, Tayler compró naranjas que embarcó para su patrón.

Puede que la anterior narración se acierta. 0 puede que no. Veámosla desde otra perspectiva. La justicia española había inmovilizado el Fortune, del que era propietario Lambert en un cincuenta por ciento, y confiscado las treinta y cinco libras que Tayler poseía. Levantada la sanción al barco y devuelto el dinero a Tayler, después de un mes de prisión, éste habría utilizado parte para afrontar gastos judiciales, avituallar el Fortune y comprar naranjas y limones para Lambert. No se había encontrado demasiado bien para ocuparse de los negocios de su patrón, pues "[he] was miserably consumed and punnished with diseases gotten by leude Women" en La Coruña, por lo que tuvo que guardar cama. Todo esto había supuesto unos gastos. Además, Tayler tuvo que encargar a un mercader, John Cave, que se hiciera cargo de los negocios, cosa que los abogados definieron muy bien, con posterioridad, con una frase latina: delegatus non potest delegare. Tayler reconoció a Cave que no tenía permiso de su patrón para pedir dinero, por lo que, parece probable, que el préstamo que solicitó en Bayona lo hiciera en nombre propio. En efecto, Lambert no se hizo responsable de la deuda. Tayler regresó a Inglaterra en el Fortune, pero huyó al llegar a Gravesend ${ }^{55}$. Era de esperar. Tayler era el prototipo de persona a la que van dedicadas algunas de las frases que recoge el autor de The marchants avizo:

What winneth a man by whordome? Euen but a momentary pleasure, a present sorrow to his minde; a perpetuall sicknes to his bodie, and eternall damnation (without hartie repentance and amendment) to his soul ${ }^{56}$.

55 High Court of Admiralty, Examinations, 25, 23 de octubre de 1583; 17 de enero y 20 de febrero de 1584 .

56 Juan J. Lanero Fernández, opus cit., Anexo I, p. 56. 
Las condiciones de la época obligaban al factor a correr riesgos, tanto en lo personal como en lo comercial, para servir a su patrón de forma debida. En 1563 John White era factor de John Broke en Amberes. White tenía treinta y un años y llevaba doce o trece de factor de Broke, lo que indica que debió empezar siendo su aprendiz. En septiembre de ese año, White vendió paños de Broke, que le había ordenado comprar doscientos toneles de vino de Gascuña, que embarcó en Burdeos. White contrató la provisión del vino a Peter Rebawdye. Según Edward Goodman, sirviente de Broke, White

... purposelye dangeringe himselfe in the warr tyme, traveled from Antwerpe unto Burdeux, because (...) Petre Rebawdye was fallen sick by the way, beinge thought that thereby he should have ben letted from the ladinge of the said wynes accordinge to the forsaid bargaine ${ }^{57}$.

Finalmente, el vino partió para Middelburg en dos barcos de Hamburgo, y se embarcó en nombre de un mercader de Amberes. A los barcos se les entregaron contratos de fletamento falsos, extendidos en nombre del mercader francés al que se le había comprado el vino. Todo esto se hizo para impedir que barcos y vino fueran incautados por barcos normandos y bretones apostados en la Gironda ${ }^{58}$. La ética de estas transacciones puede parecer, cuando menos, dudosa, pero no podemos negar que un factor isabelino necesitaba demostrar cierta energía, valor e inventiva.

VIII

Es difícil determinar la recompensa financiera de los factores que demostraban determinadas cualidades. El sirviente de un mercader percibía un jornal. Los factores empleados por una Compañía por acciones recibían un salario de diversas maneras. Así, el agente o factor principal de la Russia Company cobraba cien libras al año, además de pensión

57 Citado en T.S. Willan, Studies in Elizabethan Foreign Trade, ed. cit., p. 28.

58 High Court of Admiralty, Examinations, 15, 3 de agosto de 1564 y 2 de octubre de 1564. Recordemos que el patrón de White es el mismo John Broke que tenía a John Bancks de factor en España. 
completa y un porcentaje de los beneficios comerciales, que se acercaba a unas ciento cincuenta libras anuales ${ }^{59}$.

Por otra parte, los factores de la East India Company recibían un poco de dinero para hacerse a la mar, y otra cantidad por expedición. La suma de ambas partes variaba dependiendo del status del factor. Los tres factores principales recibían cien libras y doscientas más por expedición. El cuarto y más bajo nivel de factor recibía veinte libras y la ganancia de otras cuarenta. Mediante este sistema, el factor percibía un interés directo de los beneficios de la Compañía, por lo que su salario dependía de la cuantía de los mismos ${ }^{60}$.

La mayoría de los factores no eran empleados de Compañías, sino de mercaderes individuales o de consorcios. Estos factores operaban a comisión, lo que da pie a Malynes para decir que el factor se puede enriquecer y "the Merchant poore, because his gaine of Factoridge is certaine, howsoeuer the successe of Merchants imployment doth prooue"61. Esto no es exactamente cierto. El factor era un empleado y el que fracasaba perdía su puesto; lo que un factor ganaba dependía del nivel de las operaciones que gestionaba y de la cantidad que cargaba por ellas, que era variable. El modelo de cuentas recogido en The marchants avizo contempla un dos y medio por ciento para ventas y compras y, a la vez, explica cómo puede calcularse ese porcentaje ${ }^{62}$ que, parece ser, fue el que imperó en la década de 1580. En la década siguiente, John Sanderson, siendo factor de la Compañía de Levante, dice que ese dos por ciento no satisfacía ni la mitad de su trabajo, por lo que carga un cinco por ciento. Así lo dice el ocho de mayo de 1600 en una carta dirigida a Alexander Harris:

I take, and alwaies have taken, five per cent (or four at least) of all my frends or foes that committ any ther matters to me (...). Hearafter I will, by Gods grace, take

$32-33$.

cit., p. 81
59 T.S. Willan, The Early History of the Russia Company, 1553-1603, ed. cit., pp.

60 Henry Stevens of Vermont, The Dawn of British Trade to the East Indies, ed.

61 Gerard Malynes, Consvtvdo, Vel Lex Mercatoria, ed. cit., p. 111.

62 Juan J. Lanero Fernández, opus cit., Anexo I, pp. 26-45. 
allwayes five per cent (...). They that find cheaper factors, lett them use them...63.

No está de más recordar aquí que, ya en el siglo XV, los factores venecianos en Constantinopla percibían un dos por ciento sobre ventas y un uno por ciento sobre compras:

... [the] uses of joint ownership were closely linked to the widespread employment by Venetians of commission agents. Most of Andrea Barbarigo's business abroad was done by consigning wares to agents. According to the standard rates, they received 2 per cent of the value of the wares they sold, and 1 per cent on purchases and collections $^{64}$.

Por otra parte, Abraham Reynolds sostiene que, en 1591, un factor en Marruecos percibía un cinco por ciento de sus ventas y compras $^{65}$. Es probable que el porcentaje que se le daba a un factor fuera más elevado en países en donde la salud y la vida corrían más peligro. La escasez de referencias al tema, por parte de mercaderes y factores, indica que existía un porcentaje establecido y reconocido: dos y medio por ciento, al menos en Europa.

Es indudable que algunos factores, que consideraban insuficiente el porcentaje que recibían, caían en la tentación de abusar de su posición de confianza. Así, algunos factores, que eran empleados de Compañías, tenían negocios privados, lo que estaba prohibido. Otros defraudaban en cantidades pequeñas, lo que es difícil de detectar, o en malversaciones más espectaculares, que sí dejaban rastro. En 1589, el Consejo del Reino (Privy Council), inició acciones, en nombre de tres mercaderes londinenses, contra sus factores en Génova, William Aldey y Thomas Hunte, que, abusando de la confianza de sus patrones, dejaron que parte de la mercancía se estropeara, no les rindieron cuentas durante tres años y huyeron a Argel con el resto de la mercancía, valorada en mil

ed. cit., p. 202.

63 Sir William Foster, The Travels of John Sanderson in the Levant, 1584-1602,

64 Frederick C. Lane, Andrea Barbarigo, Merchant of Venice, 1418-1449, Baltimore: The Johns Hopkins Press, 1944, p. 93. Este porcentaje es el que está recogido en el Libro Mayor que Jacomo Badoer llevaba en Constantinopla y que va de 1436 a 1438 ( A. S. V., Cinque Savii, ser. i, Diversorum, busta 958, K. 4). Se trata de un Libro Mayor que contiene, fundamentalmente, cuentas de factores o agentes comisionados. También puede verse este porcentaje en los libros de cuentas de Contarini que se conservan en el Museo Cívico de Venecia, Archivio Tron-Donà.

65 Court of Requests, Proceedings, 75/30. 
quinientas libras ${ }^{66}$. Nueve años después, un factor en Marruecos desapareció con seis mil libras de sus patrones, lo que le causó la muerte a uno de ellos, "overtaken with greefe and sickness died in prosecution of the cause" $^{\prime 67}$. En 1586, Henry Alington tuvo que pedir una demora a sus acreedores porque se encontraba "behoynd (sic) hande by the slipping asyde of his factour"68.

En el extremo opuesto, el factor podía verse recompensado por su patrón. Sir Roger Martin legó, en 1573, a William Rawlyns, uno de sus factores en Hamburgo, cien libras. Ralph Greneway hizo lo mismo, en 1588, con Richard Soday, su factor en España, a quien dejó cuarenta libras. Soday era cuñado de Greneway. Emplear a parientes como factores era frecuente ${ }^{69}$. En 1584, Robert Lawrence era aprendiz de su hermano Nicholas, que lo destinó a Noruega para que fuese su factor ${ }^{70}$. Años más tarde, Thomas Starkey envió a Marruecos a su hijo mayor, Mathew, para que fuera su factor ${ }^{71}$. Declarar heredero a un factor, en ocasiones, llevaba aparejado que éste se encargara de solucionar los asuntos de su patrón, o que continuara siendo un fiel servidor de su viuda. Si ésta proseguía con el negocio de su marido, solía mantener a su factor.

La muerte de un mercader podía significar una herencia para el factor fiel, o un ajuste de cuentas, y en ambos sentidos, para el negligente y corrupto. Cuando William Handforde murió en 1582, su factor en Rouen, Ralph Letherborough, no le había rendido cuentas durante cuatro años. Handforde había contratado a un joven de Newcastle, Giles Cox, para que le llevara la contabilidad. Lo envió tres veces a Francia para que revisara las cuentas de Letherborough. Cox averiguó que, entre unas cosas y otras, debía a su patrón doscientas treinta y cinco libras, de las que cincuenta y cinco eran en concepto de "provision done for the said Letherborowghe here in England". Letherborough confiaba que su patrón se las perdonaría "for acquayntance and good service bye factorshippe". Las ciento ochenta restantes no se las podía pagar, pues el paño de su

\footnotetext{
66 Acts of the Privy Council of England, 1589-90, pp. 201-202.

67 Acts of the Privy Council of England, 1597-98, pp. 632-363.

68 Acts of the Privy Council of England, 1586-87, p. 251.

69 T.S. Willan, The Muscovy Merchants of 1555, Manchester University Press, 1953, pp. 43-44.

70 High Court of Admiralty, Examinations, 22 de octubre de 1584.

71 Prerogative Court of Canterbury, 3 Dixy.
} 
patrón se lo había vendido a crédito a un italiano. Cox le ofreció rebajarle quince libras por cada cien que le entregara en metálico. Letherborough rechazó la oferta. Handforde murió debiendo quinientas libras a Richard Martin, que denunció a Letherborough por parte de la deuda. Desconocemos cómo acabó el caso. Es posible que Letherborough pasara por un mal momento cuando falleció su patrón, aunque todo parece indicar que no era la clase de factor que pudiera esperar una herencia por los servicios prestados $^{72}$.

IX

Sería interesante saber si los factores utilizaban esas herencias como capital con el que iniciar una carrera de mercader. No existen demasiadas pruebas documentales, aunque parece estar claro que el paso de factor a mercader era habitual. Thomas Alabaster, por ejemplo, era factor en España en 1588; once años más tarde, tenía intereses comerciales en este país, aunque como mercader ${ }^{73}$. William Resould, factor en Bayona en 1587, se convirtió en un mercader que iba a comerciar con Marruecos ${ }^{74}$. Paul Baning exportaba cables y cabos a Lisboa, y cáñamo y lino a Francia en 1576, tan solo cuatro años después de oficiar de factor en España ${ }^{75}$. Se trataba de una evolución natural para los más capaces, ambiciosos y emprendedores.

También existieron, sin duda, los factores que vivieron y murieron siendo tales, y que nunca fueron mercaderes. En su condición de factores desempeñaron un importante papel en el comercio exterior inglés. Sin su existencia, la organización del comercio hubiera sido más difícil y lenta. Con ellos, la organización comercial se convirtió en flexible, al tiempo que en compleja. Los detalles de esa organización habrían sido más claros si los factores hubieran hablado más, pero exceptuando los tribunales de justicia y las cartas comerciales, su expresión fue el silencio. John Sanderson, al que hemos aludido en este estudio, y que escribió su

\footnotetext{
72 High Court of Admiralty, Examinations, 25, 19 de octubre de 1583.

73 High Court of Admiralty, 27, 14 de marzo de 1588; 33, 9 de febrero de 1599.

74 Exchequer, King's Remembrancer, Port Books, 7/7; Court of Requests, Proceedings, 75/30.

75 Exchequer, King's Remembrancer, Port Books, 6/4.
} 
vida y viajes, no fue más que una excepción a la norma ${ }^{76}$. Además, el agente siempre está eclipsado por el principal, y el factor por el mercader.

Sir William Monson resumió la distinción entre mercader y factor afirmando: "Learning is as much to be preferred before war as the trade of a merchant before that of the factor"77. En efecto: es preferible educar que guerrear, como lo es comerciar con un mercader antes que con un factor. No deja de ser una comparación sorprendente en un almirante.

\section{BIBLIOGRAFÍA}

Acts of the Privy Council of England, 1586-87.

Acts of the Privy Council of England, 1589-90.

Acts of the Privy Council of England, 1597-98.

AlberTI, L. de and A.B.W. Chapman (1909) "English Traders and the Spanish Inquisition in the Canaries", Transactions of the Royal Historical Society, Third Series, III, pp. 237-253.

BISSON, Douglas R. (1993) The Merchant Adventurers of England: The Company and the Crown, 1474-1564. Newark: University of Delaware Press.

Calendar of the Manuscripts of Major-General Lord Sackville (1551-1612) Preserved at Knole, Sevenoaks, Kent, Cranfield Papers, Ed. A.P. Newton, London: His Majesty's Stationery Office, 1940.

Calendar of State Papers, Domestic Series of the Reign of Elisabeth (1591-1594) Preserved in Her Majesty's Public Record Office, Ed. Mary Anne Everett Green, London: Longmans, Green, Reader and Dyer, 1867.

ELMHIRST, Edward Mars (1959) Merchants' Marks. Ed. Leslie Dow. London: Publications of The Harleian Society.

1602, ed. cit.

76 Sir William Foster, ed., The Travels of John Sanderson in the Levant, 1584-

77 M. Oppenheim, ed., The Naval Tracts of Sir William Monson, in six books, Printed for the Navy Records Society, 1902, vol. I, p. 104. 
FOSTER, Sir William, ed. (1931) The Travels of John Sanderson in the Levant, 1584-1602. With His Autobiography and Selections from His Correspondence. London: Printed for the Hakluyt Society.

-, ed. (1940) The Voyages of Sir James Lancaster to Brazil and the East Indies, 1591-1603. London: Printed for the Hakluyt Society.

[FULLER, Thomas] (1811) The History of the Worthies of England: Endeavoured by Thomas Fuller, First Printed in 1662. A New Edition, with a Few Explanatory Notes by John Nichols, 2 vols., London, Edinburgh \& Perth: Printed for F. C. and J. Rivington et al..

GRASS, Norman Scott Brien (1918) The Early English Customs System: A Documentary Study of the Institutional and Economic History of the Customs from the Thirteenth to the Sixteenth Century. Cambridge, Mass: Harvard University Press.

HANBURY, Harold Greville (1960) The Principles of Agency. London: Stevens \& Sons Limited.

High Court of Admiralty: 1588, 1599.

High Court of Admiralty, Examinations: 1564, 1565, 1567, 1568, 1569, 1572, 1575, 1583, 1584, 1585, 1587, 1594.

LANE, Frederick C. (1944) Andrea Barbarigo, Merchant of Venice, 14181449. Baltimore: The Johns Hopkins Press.

LANERO FERNÁNDEZ, Juan J. (1995) De cómo los ingleses deben gestionar sus negocios en la península ibérica: The marchants avizo (1589), Trabajo de Investigación no publicado. Universidad de León.

LINGELBACH, W.E., ed. (1902; reprint 1971) The Merchant Adventurers, Their Laws and Ordinances. New York: B. Franklin.

- (1902) "The Internal Organization of the Merchant Adventurers", Transactions of the Royal Historical Society, 15, pp. 1-45.

MALYNES, Gerard (1622) Consvetvdo, Vel Lex Mercatoria, or The Ancient Law-Merchant. Diuided into three parts: According to the Essentiall Parts of Trafficke. Necessarie for All Statesmen, ludges, Magistrates, Temporall and Ciuile Lawyers, Mint-men, Merchants, Marriners, and All Others Negotiating in All Places of the World. London: Printed by Adam Islip.

MENDENHALL, T.C. (1953) The Shrewsbury Drapers and the Welsh Wood Trade in the XVI and XVII Centuries. Oxford University Press.

OpPenHeIM, M., ed. (1902) The Naval Tracts of Sir William Monson, in six books. Printed for the Navy Records Society. 
PEELE, James (1553) The maner and fourme how to kepe a perfecte reconyng, after the order of the moste worthie and notable accompte, of Debitour and Creditour.... London: Richard Grafton.

- (1569) The Pathe waye to perfectnes, in th'accomptes of Debitour, and Creditour.... London: Thomas Purfoote.

RICH, E.E. (1937) The Ordinance Book of the Merchants of the Staple. Cambridge University Press.

SANTOYo, Julio-César (1974) "Thomas Nicholas y el cronista de Indias Agustín de Zárate. Comentarios lingüísticos e históricos sobre la traducción inglesa de 'La Conquista del Perú' (1581)", Boletín Sancho el Sabio, Año XVIII, Tomo XVIII, pp. 555-578.

Sellers, M., ed. (1906) The Acts and Ordinances of the Eastland Company. London: Royal Historical Society.

STEVENS OF VERMONT, Henry (1886) The Dawn of British Trade to the East Indies as Recorded in Court Minutes of the East India Company, 15991603.... London: Henry Stevens \& Son.

WEDDINGTON, John (1567) A breffe instruction, and manner, how to kepe, marchantes bokes, of Accomptes, After the order of debitor and creditor.... Andwarpe: Petter van Kerberghen.

WILLAN, T.S. (1953) The Muscovy Merchants of 1555. Manchester University Press.

- (1956) The Early History of the Russia Company, 1153-1603. Manchester University Press.

- (1959) Studies in Elizabethan Foreign Trade. Manchester University Press. 